their curative powers rather less than more explicable. Consider the instances of the power of antimonials in reducing continned fever, whilst they are inoperative in periodics ; of iolites in relieving pain ; of bromides in arresting the growth of fleshy tumonrs; of guaiacum in relieving rheuratısm. \&c.

We cannot deny our deticiency in not having the numerical proportion of success and failure with respect to all these, but we are quite sure that, if we dir possess it, an advance in our knowlerlge of great value would be attained. In rathology statistical incuiries have been eminent y successful in elucidating the correlation of symptoms and disorranizatioas, the distinction of causes and effects-of invariable and contingent se. quences. They have ten fed to correct both our diannosis and prognosis, and we believe if judiciously employed they would equally benefit therapeutics.

\section{PHYSALIS ALKAKENGI.}

Happily, we are not responsible for the unconth terms in use by botanists. The public, however, seem to be satisfied with them. The above term is to be found in the orlinary lists of garden plants, to designate a perennial herbaceons plant be. longing to the natural order Solanacea, cultivated in this country because it is green and yields its berries during the winter months. The berries are used to enliven with their red colour the bouquets sold in Covent-garden when other flowers are scarce. It is, in short, the winter cherry. This plant grows wild extensively in the south of Europe, where the berries are eaten and are sometimes used to impart a ruby-red colour to beer. These berries are about the size of a cherry, nearly enveloped by a calyx, and contain numerous fit, kidneyshaped seeds. Their taste is acir, with a slight bitter. The leaves, capsules, and all parts of the plant have a strong bitter taste, which appears to reside in a principle which has been isolared and designated physalin.

The mode of obtaining this principle is as follows: The leaves and capsules are treated with chloroform, which. when saturated, is evaporated, and the residue dissolved in boiling alcohol. This solution is then decolorized by means of animal charcoal, filtered, precipitated with water, washed, and dried. Physalin is a light powder, with a shade of yellow; its taste is at first slight, but afterwards very bitter. It is slixhtly soluble in cold, more so in boiling water, very soluble in alcohol and in chliroform. It is aperient and diuretic, and has been recommended in gravel and other disorders of the urinary organs. These properties have been attributed to the plant from the time of Dioscoriles, and it has probably never been wholly discarled from domestic practice. French authors have recommended it in ischuria renalis, and it has even been extolled in epilepsy; but it seems to be destitute of the narcotic properties commonly belonging to solanaceous plants. Ray states that the berries, taken every morning, have been known to prevent the attack of gout. Recently a French physician has publisher a pampllet on the subject of gont, in which he asserts that the physulis alkakengi is a remedy more efficacious than colchicum, whilst it is devoid of the objectionable properties of the latter.

The attention of the writer was called to this substance by patients who alleged that they had experienced great and remarkable benefits from its use in overt attacks of yout, and the erratic symptoms called masked gout. On this ground alone we have deemed it proper to give it a place in these papers for experiment, without fucther vouching for its efficacy.

The French author vrepares what he calls alkakenuine in the following manner:- He takes the flowers, calvx, ant unxipe berries, carefully dries them, and reduces them to fine powder. This he makes into a moist paste with water, arlds a little slaked lime in fine powder, and treats the mass with boilin alcohol; he filters and clistils off the alcohol, and the residue is his alkakengine.

To arlminister this he mixes it with an equal portion of solution of silicate of soda, and forms it into pills with powder of the Teucrium chamadiys (germander). Of these pills he gives five or six during the day in an overt at tack of gont, and two or three for slighter symptoms, increasing or diminishing the number according to the effects observed. He preseribes at the same time an aperient, consisting of extract of colocynth and extract of cinchona bark.

It may be observed that the germander had a reputation for relieving gout before colchicum was introduced. It was one of the ingreuients of the celebrated Portland powder.

\section{MENISPERMUU FENESTRATUM.}

Calumba wood ; Calumbach ; False Columbo.-This plant, a strong woody creeper, grows plentifully in the island of Ceylon, where an infusion of the wood has long been used as a tonic bitter, and is esteemed very valuable. A few years ago a large quantity of the woody stems was imported into this country, and not being known, and consequently no demand existing for it in the market, it was sawn into slices, and sold as columbo root. A chemical examination of a specimen was made in the laboratory of st. Bartholonew's Hospital, by Mr. Jas. D. Perrins, under the superintendence of Dr. Stenhouse, and the results given in a paper in the Philosoplical Mfagazise for Aug. 1853. Previously a botanical and commercial account of it was publisher by $\mathrm{Mr}$ Daniel Hanbury, in the Pharmaceuticul Journat for 1851 . This wood was found to be very rich in an alkaloid, termed berberine, because first discovered in the root of the $B$ erberis vulgaris. This must not be confounded with bebeerine, the active uncrystalline principle of the bebeeree tree of Guiana. Berberine is a crystalline basic body, or alkaloid, forming salts with acids. It is fount in a very small uroportion in columbo root. We must not. however, suppose that becanse these three vegetables contain whas appears to be one and the save alkaloid, that they are therefore identical in their therapeutic pro. perties. They furnish an illustration of a fact noticed in a former paper,-namely, the occurrence in the same drug of several constituents of diverse properties-adjuvant, corrective, or antagonistic. The columbo contains another crystalline principle, columbine. The root in infusion, or tincture, is a simple bitter tonic, whilst the wood before us is powerfully tonic, perhaus by reason of its alkaloid, berberine, and is also aperient. With this combination of useful properties, it has no astringency, and consequently does not, like rhubarb, produce subsequent constipation. Some metropolitan practitioners who have employed it rather extensively, have formed a very favourable opinion of the tonic power of the menispermum, and consider it far more active than columbo, approaching nearly in this respect to the cinchonas, whilst it has the other advantages of columbo, in being free from all stimulating action and astringency, being congenial to the stomach, with the addition of a decided aperient action. It is further worthy of note, that an old treatise, of the date 1699, is referred to by Mr. Daniel Hanbury in the paper alluded to above, wherein this wood, probably, under the name of columbo, or calumbach wood, is extolled as curative of gout and rheumatism.

\section{MENISPERMUM CANADENSE.}

Yellow Parilla _. This plant, belonging to the same family as the above, is indigenous to North America, growing abundantly in all the States from Canada to the Mississippi. The root is the part employed. It is tonic, laxative, diuretic, alterative-properties similar to those attributer to the $M e n i$ spermum fenestratum. For tho reasons stated in a former paper, it is probable that a readier and more certain supply of the American species can be obtained than of that from the island of Ceylon, and this may recommend this drug in preference for experiment in this country. Nearly allied as the two plants are, it hy no means follows that their therapeutic actions are identical. Yellow parilla is alleged to be of great value in general debility, dyspepsia, scrofula, and many cutaneous diseases. We have not met with any analysis of this root, but its visible and therapeutic properties would seem to warrant the expectation that it contains berberine, associated with an aperient resinous or extractive matter. A concentrated preparation of parilla is in the market, and is said to represent fully its remedial value. It is desiunated menispermin. The dose of this substance is two grains repeated three times a day,

\section{Contesponderte.}

"Audi alteram partem."

\section{ON THE CONSTRUCTION OF HOSPITALS.}

\section{(LETTER FROMI MRR. CHARLES HAWKINS.)}

\section{To the Editor of THE LANCET.}

SIR, - - In your last number you say you insert a letter "in order to elicit the most recent professional experience on the most important question"-viz., the construction of hospitals. Perhaps you may find room for a few lines from me, having given some attention to the subject, and visited within the last two years some of the best-constructed hospitals in France, Italy, and Belgium. 
Last year I was waited on by one of a deputation from abroal, who visited Fngland for the purpose of informing themselves on all that we had done lately in hospital construction. When requesterl to point out the hospital in England that might serve as a model to be copied, I confess I was obliged to say that I knew of none. I trust the hospitals about to be built by the governors of St. Thomas's, and those in Leeils and Surrey, may be so constructed as to serve as models for all countries. The tirst question to be consilered is, what is the best size and plan of an hospital? In my opinion, an hospital to contain 400 , or at most :00 beds, is quite large enough for any one neighbourhood, and for all clinical purpuses, and will hold quite as many sick people as ought to be congregated in one building. As to the plan, of course this muss depend in a great measure on the value of land; and as in this country, both in Lonlon and the provincial towns, the price of land is so enormons that it appears to me to shut ont what is called the "Puvilion" plan, whatever its merits and demerits may be, and it has both, I think the best plan we can adopt is that of the letter $\mathrm{H}$; the wards being only in the wings, and the centre of the building used for the officers' apartments and the other necessary rooms and offices, \&c. \&s. The wings can be made long or short, according to the number of beds to be required. A plan of such an hospital-to contain 250 beds-I exhibited last year in the Architectural Exhibition. In this plan warils have windows on each side, which I consider a sine $q u \hat{a}$ non. The fire-place is placed in the centre of the ward, having two fices. In this plan the fire-place is so situated as more tqually to distribute the heat, and to be seen by a larger number of patients; whilst a portion of the builing throush which the chimney goes serves as a ventilating shaft.

Not to take up your space, I will briefly state what, in my opinion, is requisite in constructing an hospital. In the first place, the wards should have windows on hoth siles; no entrance to wards through corridors that cannot be ventilated, or, what is worse, no double wards; all water-closets to be placed in a portion of the building projecting from the main building, so that they can have windows on both sides. Each ward to have attached to it a lavatory, with a constant supply of hot and cold water, where the patients who are able to get up may wash themselves; also a room fitted with slate shelves, where the provisions of the patients-such as bread, butter, and milk for the lay-may be placed, and not, as now they usually are, on shelves over the bet; ; room also to contain the clothes of the patients-not to be placed as they now are in boxes close to, or, what is worse, under the patients' beds. If there are nurses' rooms, large windows in them, so that they may have a view of the patients (and no green blinds allowed in these rooms, so as to do away with their use). Uf course it is not requisite to mention the necessity of having hot and cold baths, lifts, \&c.

In an hospital such as I have mentioned, there should be at least three large staircases : one in each wing for the patients (and if the wings are long, two may be required); and one in the centre of the building for the use of those in the hospital not patients. All these staircases should have an opening in the roof, filled in with perforated zinc, and covered for protection from rain by a raised zinc chimney or cowl. Such a plan has been adopted at St. George's Huspital with good results. The windows in the wards should be like those in use in the Midd!esex and St. Greorge's, opening by a very simple arrangement in three or four divisions, the quantity of open space being regulated according to the quantity of fresh air required.

As to the grand point, ventilation, I must confess that I have very little faith in what is called "scientifie" ventilation, and I have seen a good deal of it. The ventilation of an hospital may be effected in a different mode to what may be required in large buildings containing a vast number of people, such as churches and theatres. I believe the ventilation of an hospital to be a very simple matter. Let the wards be built as I have advised; the windows kept almost constantly open, however small a portion of them; the staircases, halls, and corridors large, and warmed when necessary with hot water; Dr. Arnott's rentilators in the chimneys; all water-closets being well shut from, although communicating with, the waris; all offensive dressings, \&c., to be immediately removed from the wards.

Regarding the size of wards, I think they should not be too large nor too small; from 20 to 25 beds in each; from 1500 to 2000 cubic feet of $s$ ace to each patient; waris not too lofty; windows reaching within nine inches of the ceiling; and at least six feet space between the beds. Wards thus constructed, and priper attention being paid by the attenclants to the means of ventilation, will be kept as sweet and pure as rooms can be containing a number of sick people.
I cannot conclude these remarks without strongly expressing my decided opinion of the absolute necessity of every hospital containing convalescent waris. Such wards have lately been constructed in St. George's Hospital; but as they were made at my suggestion, and after my plans, I would rather quote what is thought of them by others. The following is from the Annual Report of the hosuital, just published:-

"'The two day wards at the top of the hospital, nsed as convalescent wards, have proved very beneficial; and the Weekly Board consider the following extract from a clinical lecture, delivered at the hospital by Mr. Preseott Hewett, one of the surgeons to the hospital, will be very acceptable and interesting:- 'As for pyæmia, in hospital practice, that, I am happy to sity, is less frequent in the wards of St. George's Hospital than it used to be; indeed, for the last two or three years, our wards have been remarkably fiee from this bane of surgery; and for this improvement there is no doubt that we are mainl indebted to our convalescent wards-the large well-aired rooms which have lately been built at the top of the hospital. These convaltscent wards I consider to be of the utmost use, not only to the patients who are thus enabled in all weathers to get out of their own wards, but also to the patients who may still be oblised to remain in bed; the general wards are relieved of a certain number of patients during a great part of the day, and both sets of patients thus have a purer atmosphere to breathe."

There is also one other subject well worthy the consideration of governors of hospitals: the desirability of spending a little money in ornamentation of the vards. $£ 40$ or $£ 50$ will go a long way, in a large hospital, in giving to the wards an appearance of something like decorative art; and such a modest outlay will tend to enliven the spirits and hasten the cure of many a patient now doomed to bave nothing on which to rest a restless eye than the eternal whiterash of most hospitals. A little shade of colour introduced in to the wash for the walls, with a party-coloured border, is all that is required, with 2 few well-selected engravings.

To perfection in drainage it is hardly necessary to allude. The remarks I have ventured to bring before you are necessarily brief, and only touch on some of the most salient points in hospital construction. If I had more time, I would lay before the profession some extended observations; but thanking you for the space you have afforded me,

Savile-row, July, 1862. I am, Sir, yours \&c.

\section{THE CHARITY OF THE TURF. (LETTER FROM MR. BOND.)}

"There was a certain rich man, which was clothed in purple and fine linen, and fired sumptuously every day.

"And there was a certain beggar, named Lazarus, which was laid at his gate, full of sores, and desiring to be fed with the crumbs which fell from the rich man's table."

\section{To the Editor of THE LANCET.}

SIR, - I beg to express to you my deep obligations for your able advocacy in a recent number, in an article headed "Philanthropy of the Turf." For the honourable mention made therein of myself, I can only say that $I$ wish I was as conscious of deserving it as I am of fully appreciating its worth. In request. ing a brief space in your valuable journal, I desire only to confirm the statement made by you, and having special reference to my name and policy. I beg distinctly to state, there. fore, that in the renewed expression of my determination to uphold the proposition made in my former letter, addressed to the Jockey Club, September, 1850, I disclaim all desire to dictate to any creature on earth as to what form his benevolence is to be exercised. My constant endeavour will be to place the turf, as an institution, in closer affinity with the sick poor of our needy and unendowed London hospitals; and this encieavour, I begr to observe, will not be violent and transient, but steady and continued, prosecuted and persevered in with all the humble ability I possess, and with total contempt of censure, sneers, or wonder, and animated, I hope, by resolution not to stop while more can be done.

That a community like racing, with an augmenting fund, at present equal to abont $£ 200.000$ per annum, should exis in England without contributing - say, five per cent. - to our hardworked, suffering metropolitan charities, is a fact which $I$, as 